\title{
Neurological modulation of facial expressions in pigs and implications for production
}

\author{
Daniel Mota-Rojas (iD . Agustín Orihuela (iD. Julio Martínez-Burnes (iD . Jocelyn Gómez • Patricia Mora-Medina (iD. \\ Belen Alavez • Luisa Ramírez • Miguel González-Lozano iD
}

D Mota-Rojas (Corresponding author) - J Gómez • B Alavez Neurophysiology, behaviour and animal welfare assessment. Department of Animal Production and Agriculture, Universidad Autónoma Metropolitana, Xochimilco campus, Mexico City, Mexico.

\section{A Orihuela}

Facultad de Ciencias Agropecuarias, Universidad Autónoma del Estado de Morelos, Cuernavaca, Morelos, México.

\section{J Martínez-Burnes}

Graduate and Research Department, Facultad de Medicina Veterinaria y Zootecnia, Universidad Autónoma de Tamaulipas, Victoria City, Tamaulipas, Mexico. email:dmota@correo.xoc.uam.mx

\section{P Mora-Medina}

Livestock Science Department, Universidad Nacional Autónoma de México (UNAM), Facultad de Estudios Superiores Cuautitlán, State of Mexico, Mexico.

\section{Ramírez • M González-Lozano}

Facultad de Medicina Veterinaria y Zootecnia. (CEIEPP), Universidad Nacional Autónoma de México (UNAM), Mexico City. Mexico.

Received: May 17, 2020 • Accepted: June 04, 2020 • Published Online: June 27, 2020

\begin{abstract}
The facial expressions of animals constitute a means of manifesting emotions, fulfilling functions related to social interactions in several species. Interest has come to use facial expressions as a tool for predicting intentions; in the case of aggression, for example, impeding attacks between individuals prevents negative economic and emotional impacts. Recent research has sought to associate facial expressions with painful events as tail-cropping and castration on the assumption that objective evaluations of the presence or absence of grimaces in pigs' snouts may allow us to determine the intensity of the pain they perceive. Furthermore, to continue developing scales that will complement the existing piglet grimace scale (PGS), which is not yet fully-validated in terms of reliability. Another area of research is interpreting expressions of fear during traumatic events like pre-slaughter handling. Also, the phenomenon of emotional contagion in groups of animals suggests the need to focus on their emotions, since recognizing them could allow us to prevent alterations of meat quality. These approaches reveal the need for a detailed compilation of the facial expressions of pigs based on current scientific literature regarding emotions, alimentation, and pain-related behavioral responses in pigs.
\end{abstract}

Keywords: behavior, emotion, facial expression, pain, pigs, production

\section{Introduction}

Emotions are mediated by the limbic system and its two sensory pathways. When stimulated, these pathways facilitate the distribution of emotional states towards limbic centers (Bruce et al 1995; Farb et al 1998; Boissy et al 2007; Whittaker and Marsh 2019). The different means through which emotions can be communicated and expressed include both, their physiological and behavioral components. However, these affective states are difficult to interpret, so new alternatives for evaluating them need to be explored. Nowadays, emotional experiences are assessed in terms of their perceived and recognizing; that is, positively $v s$. negatively, gratifying vs. punitive, or pleasant vs. unpleasant (Mellor 2012; Rutherford et al 2012; Reimert et al 2013; Mellor and Beausoleil 2015).

The expressions of psychological and emotional states serve as indicators of reactions to diverse stimuli, such as pain (Manteca et al 2017; Hernández-Ávalos et al 2019), play (Brown et al 2015), delivery and birth (González-Lozano et al 2020; Mota-Rojas et al 2018a, 2020a), feeding (Frías 2015; Núñez 2015) and the factors involved in each type of behavior and the human-animal relationship (Orihuela et al 2018; MotaRojas et al 2020b). Facial expressions of animals also form an effective evolutionary tool that allows them to demonstrate emotions that reflect the mental states that occur in response to external and internal stimuli as part of a species' natural 
behavior (Darwin, 1872, cited by Müller 2019; Friel et al 2019; Lezama-García et al 2019a).

In this sense, facial expressions facilitate communication and social interaction among animals and reveal specific emotional states through which they share motivational or aversive information (Iglesias et al 2016). For this reason, facial expressions have been used as tools to recognize and quantify pain with the aid of facial expression scales, which are instruments that focus on four or five facial areas scoring specific actions as present ( 2 points), partially present (1 point) or absent ( 0 points) (McLennan et al 2019). Facial expressions are measured through the Facial Action Coding System (FACS), which assesses multiple changes in the facial muscles called "facial action units" (FAU) (McLennan 2018). Today, we have a facial expression scale for piglets subjected to tail-cropping and castration that could pave the way for new research on this topic, as in the case of pre-slaughter handling in abattoirs that directly affects both animal welfare and meat quality. Given this background, it is necessary to elaborate a detailed compilation of the facial expressions of pigs based on the scientific literature generated to date on their emotions, feeding, and behaviors related to pain responses. This review aims to propose for discussion, and analyze, the topics that form the bases of the study of facial expressions in domestic animals that, to date, have been viewed as polemical due to the difficulty involved, first, in elaborating, and then evaluating, protocols for such studies. While the analysis of the facial expressions of domestic animals is still in the early stages of its evolution, this review was conceived as an antecedent that will facilitate the development of assays and the generation of new knowledge regarding Animal Welfare and its assessment in farm animals.

\section{Importance of facial expressions and animal welfare}

Any reference to facial expressions must go hand-inhand with the analysis of the emotional states of animals in an approach that requires the combined use of validated tools to ensure the accuracy of observations made by humans. In this regard, we have the Facial Action Coding System (FACS), which was developed to evaluate facial behavior in humans based on the movements of individual facial muscles (Ekman and Friesen, 1978). This system has been modified over time for use with certain species of non-human primates and domestic animals (dogs, cats, horses), but additional research is required (Wathan et al 2015; Caeiro et al 2017a; Caeiro et al 2017b; Lezama-García et al 2019a; Waller et al 2020). Another tool, the so-called 'grimace scale', has been developed, and undergone a series of adaptations for different species, to validate its potential use as an instrument for identifying emotional states in animals such as pigs ( $\mathrm{Di}$ Giminiani et al 2016), horses (Dalla-Costa et al 2014), sheep (Häger et al 2017), and rats (Sotocinal et al 2011). An additional element that must be taken into account is applying a tool that is capable of measuring the emotional states of animals. In this case, we have Qualitative Behavioral Assessment (QBA), a methodology designed to integrate information from multiple behavioral signals and styles of behavioral expression (i.e., body language) in relation to emotional expressions in animals (Rutherford et al 2012). QBA was developed to replace interpretative methods that are influenced by human emotions. It is based primarily on the observation of behavioral signs in accordance with previously established criteria. Without a doubt, combining these different methods has substantial potential to aid in evaluating animal welfare, not only in experimental studies but also for the direct assessment of farm animals.

\section{Neurological modulation of facial expressions}

The first contribution to an explanation of the expression of emotions by animals, its evolution, and similarities among species is found in Charles Darwin's book, The expression of emotions in man and animals (1872). In this book, Darwin stated the existence of an evolutionary process based on the expression of observable emotions (expressive movements) and cerebral processes. Darwin suggested that some emotional expressions are innate, in the sense that the action exerted by the central nervous system regulates mechanisms that generate manifestations of those emotional states (Brudzynski 2010). Recent scientific advances have clarified that emotions are closely-mediated by the neuronal function of the limbic system, including the prefrontal, insular and cingulate cortices, the hippocampus, amygdala, and septal nuclei (Bruce et al 1995). It is important to note that two sensory pathways have direct access to the limbic system: one that runs through the olfactory nuclei directly to the amygdala, and a second that crosses the afferent nuclei of the medial geniculate body and the thalamic nuclei of acoustic signals (Farb et al 1998). It must be emphasized that all sensory modalities convert at limbic centers (including the amygdala) only after they have been processed in their respective sensory cortical areas. Through this process, emotional states are widely-distributed among the limbic centers (Boissy et al 2007).

In general, animals express emotions through diverse physiological channels that include somatic motor, hormonal, and autonomous responses (Mota-Rojas et al 2018b,c). For example, the position and movements of the head, ears, and limbs, as well as facial and vocal expressions, are classified as somatic motor responses that are manifested as corporal expressions (Brudzynski, 2010; Mota-Rojas et al 2016; MotaRojas et al 2018c). Regarding facial expressions, their potential as indicators of psychological and emotional experiences in animals is widely-accepted, so assessing them may provide valuable information on temporal or specific 
reactions to different stimuli. However, facial expressions also fulfill social and reproductive functions, and so are keys to evaluate animal welfare and not just as indicators of affective states (Descovich et al 2017). For this reason, facial expressions are studied as indicators of intention (e.g. the attack stimulus), as reflections of internal states (e.g. pain responses), and as measures of emotional states (Camerlink et al 2018).

It is important to emphasize that facial expressions can determine generalized or specific patterns in individual species, as well as incidences of variation among individuals. According to Descovich et al (2017), there are already reliable systems for recording and measuring facial expressions that are highly-valid for various taxa, because they consider the characteristics and differences of certain species. In the case of pigs, from an anatomical and more specific perspective, we have breeds with distinctive snouts whose movements are controlled primarily by contractions of the elevator muscle of the upper lip (musculus levator labii superioris). Pigs' lips are relatively short but have sufficient mobility, even though these animals cannot open their mouths widely. Their eyes, meanwhile, are small and deep-set (Dyce et al 2010).

Nowadays, it can be confirmed that animals have both, the capacity to experience diverse emotions regulated by complex limbic systems and to use multiple communication channels to transmit and/or manifest their emotional states. One such mechanism consists of facial expressions, which can accurately reflect an animal's internal state; hence they are considered significant indicators of animal welfare (LezamaGarcía et al 2019a; Mota-Rojas et al 2016; 2018b,c).

\section{Types of emotions}

Emotions are mental states expressed in response to external and internal stimuli. They are integral parts of an animal's behavior that can be classified into two dimensions: as a function of emotional valence and/or excitation. Evaluations are based on such behaviors as body posture, facial expressions, and vocalizations (Friel et al 2019). Emotional valence can be codified in terms of the duration of vocalizations; for example, the grunts produced in contexts with positive valence are longer than those generated in negative settings. Because the duration of vocalizations is affected by respiration, changes in the action or tension of the respiratory muscles may explain the lesser duration of vocalizations in negative contexts (Friel et al 2019). Emotional experiences, therefore, are evaluated by how they are perceived; that is, as positive/negative, gratifying/punitive, or pleasant/unpleasant, while excitation can be defined as an emotional activation in which the animal's body experiences elevated physiological activity and extreme emotion, whether positive, as in the case of excitation, or negative, as in the case of rage (Reimert et al 2013; Leliveld et al 2016; Marcet-Rius et al 2019a).

In the case of pigs, positive emotions can be identified by signs of playfulness, grunting, and movements of the tail, while negative ones may be manifested by freezing, defecation, miction, attempts to escape, acute vocalizations (screams, shrieks), lowered tails, and ears pressed backward or in movement (Reimert et al 2013). A study by Marcet-Rius et al. (2019b) observed 6 pens, each with 6 pigs but distinct forms of environmental enrichment. The objective was to analyze possible indicators of emotions (placing special attention on the frequency and duration of ear and tail movements). Those authors found a positive correlation between the duration and frequency of tail movements while the animals were interacting with the enrichment materials. Their observations suggest that a high frequency of tail movements could be linked to positive emotions, in this case, related to the type of environmental enrichment materials present and, more specifically, to exploratory behavior, which is highly important in pigs. However, it is necessary to conduct additional studies with different enrichment materials measuring other indicators of emotions to understand in greater depth the detonators of positive emotions in pigs and their relation to increased tail movements before this behavior can be employed as a reliable indicator that would allow researchers to conclude that emotions like fear and anxiety could have a great impact on the behavior, health, and welfare of animals (Marcet-Rius et al 2019a; Orihuela et al 2018; Mota-Rojas et al 2018c).

Emotions contain behavioral, neurophysiological, cognitive, and conscious components, even though animals have primarily been measured behavioral or physiological components (Reimert et al 2013). Krugmann et al (2019), carried out a study designed to determine the behavioral patterns of pigs on 3 farms that used distinct housing systems. They mention that the approach tests to unknown humans or novel objects may be the adequate indicators for evaluating the levels of anxiety and fear that the animals experience. They affirmed that the pigs seemed to be able to manifest stronger or weaker motivations to explore new stimuli, though this finding makes it difficult to reach a clear conclusion as to whether high or low levels of exploratory motivation indicate positive or negative emotions. Other studies suggest that a certain frequency of ear movements is a direct indicator of negative emotions, a frequency that was significantly greater in conditions without distractors in comparison with enriched environmental settings (Marcet-Rius et al 2018; Marcet-Rius et al 2019a).

In light of the importance of swine welfare, it is necessary to study emotions based on the assumption that positive emotional states contribute to improving welfare, while negative ones reduce it (Murphy et al 2014). In this case, to evaluate the welfare of animals that are housed in groups 
like pigs it is extremely important to consider not only the emotional states of individual animals but also the degree to which companions in the pen are affected by the anguish or pleasure felt by others, because the phenomenon known as 'emotional contagion' can have serious implications for animal welfare, particularly in those kept in large numbers in the same pen, where contagion translates into a simple form of empathy (Reimert et al 2013).

\section{Implications of facial expressions for production}

The facial expressions of production species like pigs have been considered a way to manifest emotions when they occur during events in response to changes in psychosocial states (Fridlund 1994). Thus, recognizing facial expressions is now seen as a non-invasive method for quantitatively evaluating emotional states in animals, under the hypothesis that this information is related to an animal's perception, or the emotional valence, of a given situation (Horstmann 2003). The contents that have been evaluated based on gestures manifested during different emotional events include expressions related to aggression, feeding, general pain, preslaughter handling and euthanasia.

\section{Expressions related to aggression}

One behavior that has received great attention is that of aggression between individuals. Aggression is a problem for animal welfare because it negatively affects individuals' emotional states (Lane and Briffa, 2017; Lezama-García et al 2019b). For example, when an individual displays a signal that indicates an aggressive intention and this is not counteracted by the receptor animal, an aggressive event may be triggered. Hence, if the initial signal of aggression can be perceived in time, then attacks or intensification to a higher level of agonistic behavior may be avoided (Waller et al 2017; Camerlink et al 2018). In this regard, Camerlink et al (2018) evaluated 38 pigs (26 males, 12 females) of a commercial crossbreed (Large White x Landrace x American Hampshire) to identify facial expressions related to aggression and its onset. Quantification of the differences in facial metrics in distinct contexts of negative emotional states was conducted by videotaping before aggression, during the aggression, and during the retreat from the attack. Results showed that before the aggressive event, the proportions of the pigs' snouts were smaller and that the animals eventually considered 'winners' showed a tendency to push their ears forward compared to those classified as 'losers'. When the pigs were separated, their ears were seen to be pushed backward, and their eyes were less wide open. The authors concluded that facial expressions could signal intentions and reflect emotional states and responses when assessed during aggressive behaviors in pigs by paying special attention to three aspects; namely, ear angle, the length/height ratio of the snout, and the position of the eyes.

Assessing the intentions and emotional states manifested in animals' facial impressions or expressions provides valuable information for evaluators seeking to prevent inter-individual aggression. However, it is also interesting to analyze the consequences of aggressions and other emotional states, especially concerning productivity, the immune status of animals, and the possibility of economic losses.

\section{Facial expressions and feeding behavior}

To improve evaluations of animal welfare and understanding animals' needs (Murphy et al 2014; MarcetRius et al 2018), research into their emotions and the best way to study them has deepened with the aid of methods that analyze behaviors and physiological changes in swine production (Temple et al 2011). Examples of the behaviors evaluated include play (Brown et al 2015) and tail movements (Reimert et al 2013), both of which are considered indicators of positive emotions (Boissy et al 2007). In contrast, movements of the ears, agonistic behaviors, and biting may indicate negative emotions (Reimert et al 2013). Unfortunately, these behavioral and physiological changes are often unspecific or difficult to interpret, so there is a danger of generating poor or inadequate classifications of the different types of emotional responses (Paul et al 2005; Murphy et al 2014; Paul and Mendl, 2018).

Concerning feeding behavior in pigs, Carcò et al (2018) define this as a set of strategies adopted to succeed in ingesting desirable food, arguing that can be measured in terms of the number and duration of visits to feeding troughs. However, diverse factors are involved in feeding; for example, the composition of the diet, sex, physiological stage, ambient temperature, housing conditions, social interaction, and states of health, among others (Boumans et al 2015; Boumans et al 2018). As a result, the mechanisms involved in feeding behavior in pigs remain unclear (Boumans et al 2015), and more research is required to properly evaluate hedonistic reactions during feeding (Figueroa et al 2015; Maselyne et al 2015).

\section{Facial expressions associated with pain}

In recent decades, the welfare of farm animals has become increasingly important as more people show interest in the handling of farm animals destined for human consumption (McLennan, 2018) and laboratory animals (Whittaker and Howarth 2014). Here, including evaluations of pain constitutes a relatively recent addition to definitions of animal welfare, but one that is having a significant impact on veterinary education and various fields of science (Mota-Rojas et al 2016; Herskin and Di Giminiani, 2018; Mota-Rojas et al 
2018b). There is no longer any doubt that farm animals are beings capable of feeling and perceiving states, both pleasant and aversive, and that pain is probably the most important affective state since it impacts animal welfare and has direct implications for both production and the quality of life of animals (McLennan, 2018). For these reasons, determining the pain that farm animals suffer is vital, and if we cannot recognize and evaluate pain, then it will be impossible to implement measures designed to provide adequate attention and treatment (Descovich et al 2017; Mota-Rojas et al 2018b; McLennan et al 2019).

Pain is one aspect of a process that combines sensory, cognitive, and affective elements. It can be described as a phenomenon of perception that gathers information from a harmful stimulus (e.g. tissue damage) through specialized sensory receptors (nociceptors) mediated by ascendant and descendant spinal and supra-spinal mechanisms. This process ends in a sensory experience with a negative emotional valence in the brain (Nalon et al 2015). The International Association for the Study of Pain defines this phenomenon as "An unpleasant sensory or emotional experience associated with real or potential damage in a tissue or described in terms of such damage" (including humans and animals) (Meskey and Bogduk, 1994). It is clear that distinct regions of the brain participate in pain, especially the somatosensorial cortex, which plays a fundamental role in perceiving and controlling it (Herskin and Di Giminiani, 2018). It turns out that pigs are one of the least-studied species in terms of the causes and indicators of pain. The limited knowledge in this field is paradoxical in light of the high consumption of pork worldwide, and this species' great value as a study model in science (Herskin and Di Giminiani, 2018). Some researchers have been conducting studies in areas like animal welfare to establish bases for examining and expanding our knowledge and evaluations of the mechanisms involved in pain and identifying pain in pigs.

It is important to recognize that methods for evaluating pain depend on general behavioral changes and that recent studies demonstrate the efficacy of evaluating changes in facial expressions (Manteca et al 2017). Measuring facial expressions entails assessing multiple variations in the facial muscles (or groups of muscles) that are called "facial action units" (FAU) in response to emotional stimuli (McLennan, 2018). According to Di Giminiani et al.'s scale (2016), a value of 0.95 for the inter-class correlation coefficient (ICC) of the facial action unit that consists of closing the orbital area, corresponds to the facial expression that occurs most often during states of pain.

Though many indicators of pain have been proposed for swine, not all of them have been validated (Sneddon et al 2014), so it is important to understand that there is no 'gold standard' for determining the existence or intensity of pain in this species (Rutherford, 2002). One obstacle reported in performing measurements is the difficulty in systematically recognizing facial expressions and quantifying pain on that basis (Di Giminiani et al 2016). For this reason, making effective evaluations of pain based on facial expressions will require overcoming the challenges and limitations of the FAU method (McLennan et al 2019). Finally, it is important to affirm that pain is the affective state expressed in facial expressions that has the greatest negative influence on animal welfare. However, considering these expressions as the only indicator may not produce accurate predictions, so additional research is required to make those expressions measurable and reliably identifiable.

\section{Facial expression scales}

Several scales have been designed to evaluate changes in the facial expressions of animals based primarily on procedures or affections that involve pain. These scales function by applying a scoring system based on the morphological characteristics of the face of the animal involved that make it possible to measure expressions ( $\mathrm{Di}$ Giminiani et al 2016). In 1978, Ekman and Friesen devised the first Facial Action Codification System (FACS) using those mentioned earlier, 'facial action units' (Finka et al 2019). Their scale could measure muscular changes in the face (McLennan et al 2019). In recent years several initiatives to elaborate FAU for different animals have emerged. They now provide a broad panorama of facial movements. The species that have attracted the greatest attention in this regard are cats (Caeiro et al 2017b), horses (Wathan et al 2015), mice (Langford et al 2010), chimpanzees (Parr et al 2007) and macaque monkeys (Parr et al 2010; Julle-Danière et al 2015).

For the specific case of pain, we have instruments called 'grimace scales', which differ from those previously mentioned in that they focus on only 4 or 5 areas of the animal's face. To develop these scales, animals were subjected to painful and non-painful states to compare and score the expressions they manifested. The scores applied are 'present' ( 2 points), 'partially present' ( 1 point) and 'absent' ( 0 points) (Sotocinal et al 2011; Langford et al 2010; Dalla Costa et al 2014; Holden et al 2014; Di Giminiani et al 2016; McLennan et al 2019). These systems are designed to evaluate pain subjectively by scoring each part of the face with evaluators that assign scores to each specific zone. This approach allow it to detect temporary pain and determine whether it is fluctuating or persistent (McLennan, 2018).

Almost all these scales employ high-definition video camera systems to capture images of the animals' facial expressions, though others use photographs. In the former case, a specially-designed software called Rodent Face Finder $^{\circledR}$ selects photograms with clear views of an animal's face in front of the camera (Sotocinal et al 2011). This type of technology helps reduce bias during manual compilation and 
selection of images (Tuttle et al 2018). In the case of pigs, an effective scale based on the pain generated in neonates by tailcropping and castration procedures (Di Giminiani et al 2016) was created. Known as the 'piglet grimace scale' (PGS), it assesses specific facial alterations in piglets in response to acute painful states. Viscardi et al (2018) emphasize that this new tool has two advantages: it is non-invasive and obtains results quickly and easily. Their work was based on observing video recordings of 19 piglets for 24 hours, beginning before the onset of the painful stimulus. Each time that a piglet approached the camera, a fixed image of its snout was taken. After assessing a total of 627 facial images, the authors succeeded in identifying three facial action units (Figure 1) to which they assigned scores as follows: (1) orbital tension; (2) muscle tension/nose bulging; and (3) ear position; each with 3 points on a similar scoring scale (absent: 0 points; moderate: 1 point; marked: 2 points).

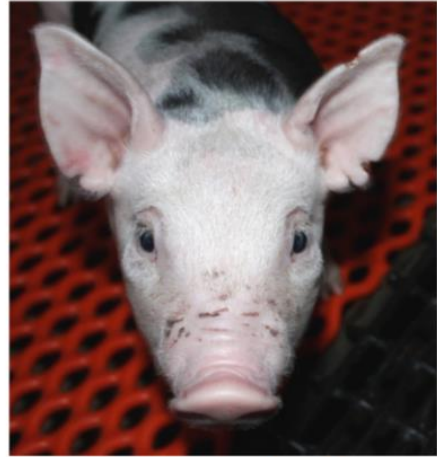

Absent (value 0)

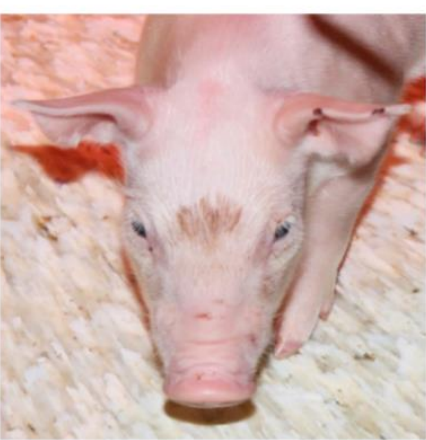

Absent (value 0)

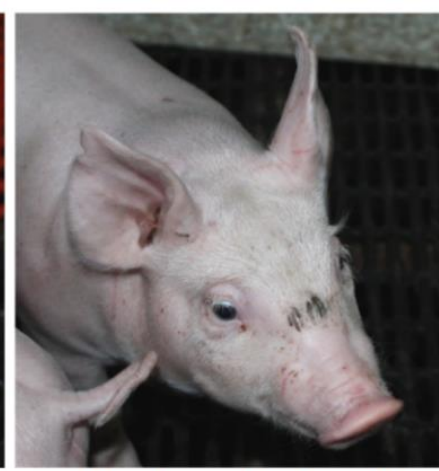

Moderate (value 1)

Ear position*

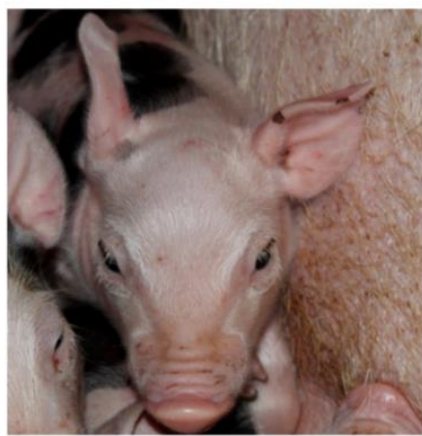

Moderate (value 1)

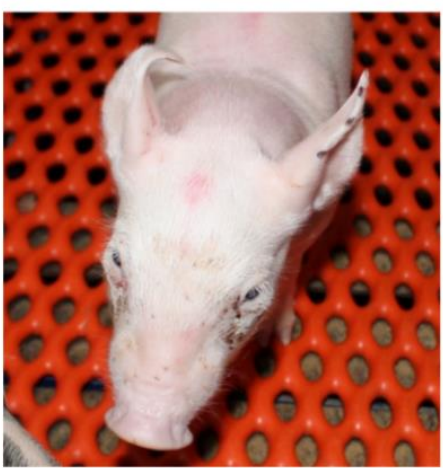

Marked (value 2)

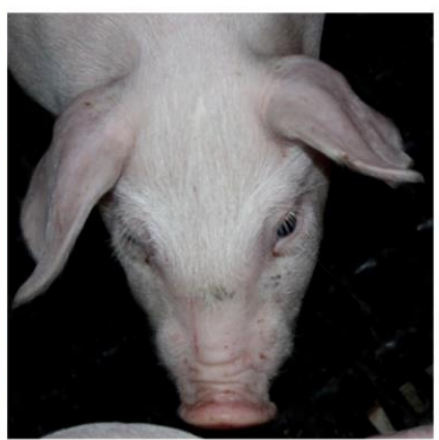

Marked (value 2)

\section{Muscle tension / Nose bulging**}

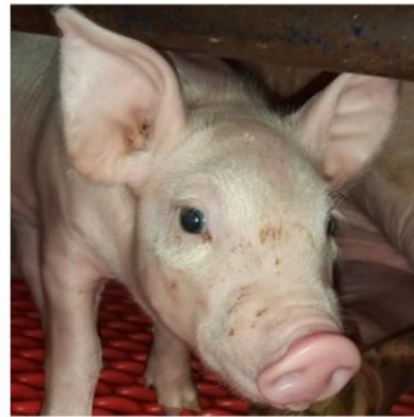

Absent (value 0)

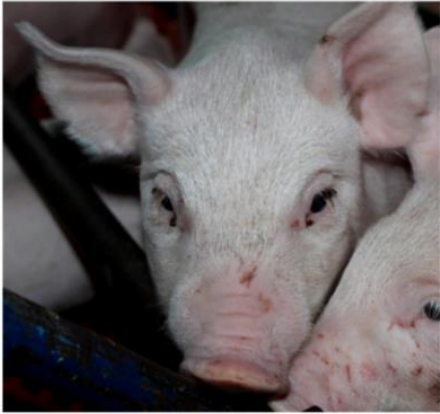

Marked (value 1)

\section{Orbital tension***}

Figure 1 Facial action units (FAU) evaluated by the piglet grimace scale (PGS). The piglet grimace scale with descriptions of each one of the three FAU applied by Viscardi et al. (2017); that is, ear position, nose tension/bulging, and orbital tension. When pigs feel pain they *, press their ears towards the caudal zone; **, show slight nose-bulging in the dorsal and lateral areas of the snout in response to muscle tension (Orbicularis oris m., Caninus m. and Musculus levator labii superioris); ${ }^{* *}$, show narrowing of the orbital area associated with tension in the eyelids (adapted from Viscardi et al 2017). 
Viscardi et al.'s work (2018), established a maximum pain score of 5 when at least two categories are grouped. Scores of ' 0 ' or ' 1 ' correspond to 'low pain', while scores of ' 3 ' to ' 5 ' indicate 'moderate-to-high pain'. These facial expression scales (FES) are easy to use and have shown a certain level of inter-observer reliability and capacity for precision. Those authors concluded that additional research is necessary to fully develop their piglet grimace scale because factors like small sample sizes could affect results. They also emphasize the need to evaluate basal behaviors in piglets to minimize possible variations that may affect assessments. It is important to mention that scales which score different levels of pain after evaluation in piglets during surgical castration or tail-cropping might undervalue the fact that pain, as such, is always present, so its intensity could cease to be relevant. These circumstances suggest that evaluating piglets' facial expressions during surgical extirpation of the testicles or other painful procedures could be more significant, interesting and precise if researchers consider interactions among the FAU (Figure 2), instead of simply attempting to determine levels of pain. This observation reflects the difficulties involved in defining the intensity and perception of pain in individual animals (also true for humans) and suggests that FAU could be used to determine different levels of interaction and, therefore, ascertain more accurate perceptions of pain in pigs.
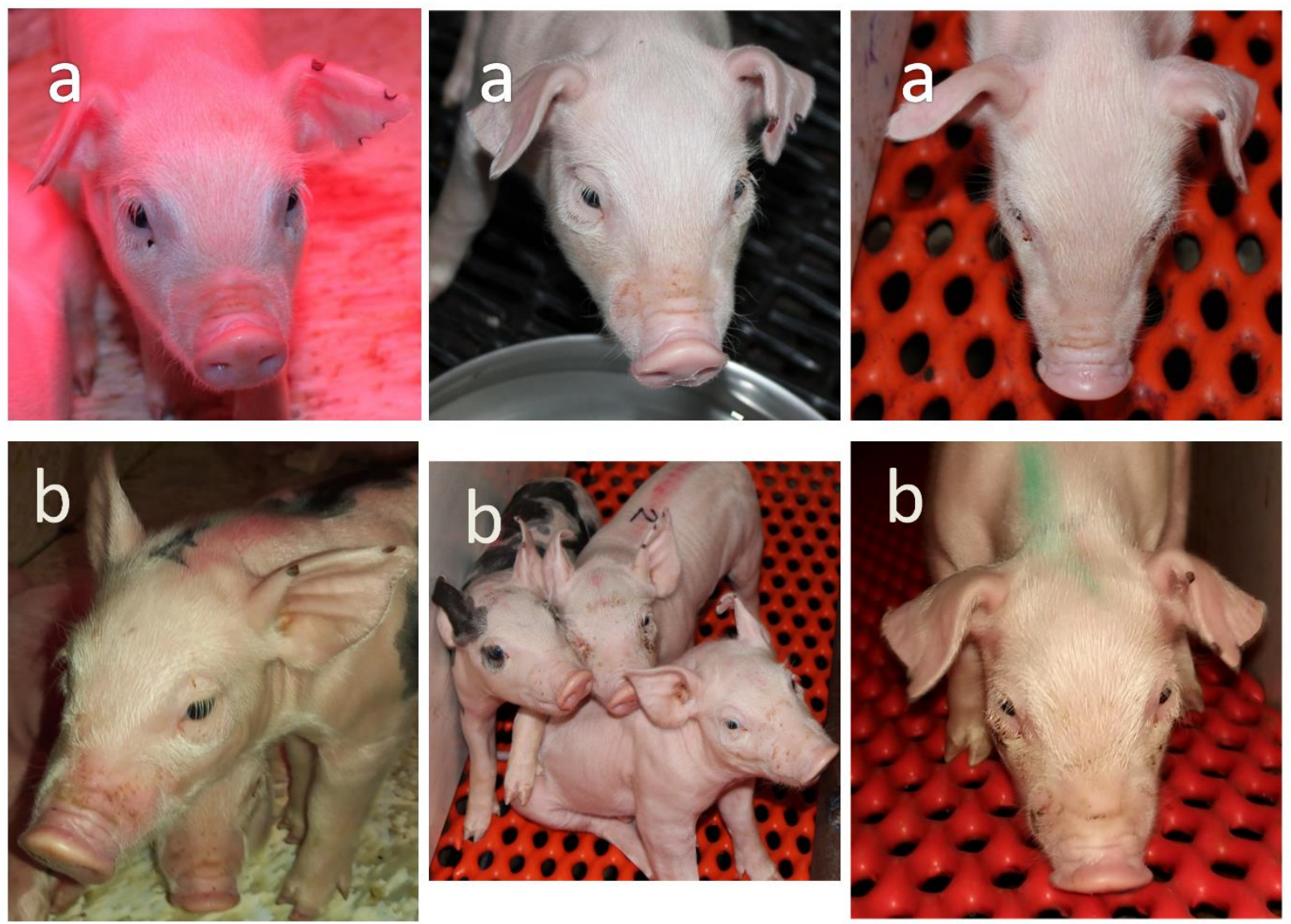

Figure 2 a. Piglets before surgical extirpation of the testicles: an alert state is identified with slight tension in the eyelids and the head raised. Note the position of the first third of the ears, which are folded towards the cranium. The snout appears to be relaxed. b. Piglets after surgical extirpation of the testicles: the animals appear to be alert, but with eyes slightly-closed due to tension in the eyelids. Slight bulging is visible on both sides of the lateral zone of the snout due to muscle tension. First and second images show the ears retracted towards the caudal zone with characteristic folding almost at the point of the ear. Finally, the piglets pile atop one another and often hit or rub their heads and snouts against the floor, as seen in the last photo.

Since the first mouse grimace scale (MGS) was introduced after a series of pain tests by Langford et al (2010), similar tools have been developed for rats (Sotocinal et al 2011), rabbits (Keating et al 2012), horses (Gleerup et al 2015), piglets (Di Giminiani et al 2016), sheep (Häger et al 2017), and cats (Bennett et al 2017). However, almost all evidence of changes in the facial expressions of animals in response to harmful stimuli has been gathered in experimental contexts, with very little research done in natural or spontaneous conditions, such as birthing (Figure 3), the weaning process in piglets (Figure 4), or specific situations that arise in swine-breeding. Accurately identifying and assessing pain entails acquiring the capacity to detect -reliably and precisely- the pain that animals suffer in real-time. Here, the use of facial expressions offers a unique, efficacious, and 
robust scientific tool that may provide significant benefits for veterinary medicine (Langford et al 2010).

\section{Pre-slaughter facial expressions and their relation to meat quality}

Handling before slaughter and during transport, loading, lairage, and conduction to the stunning line are factors that trigger stress in animals and can affect meat quality (MotaRojas et al 2006; Becerril-Herrera et al 2009; Van de Perre et al 2010; Mota-Rojas et al 2012; Vermeulen et al 2015; FloresPeinado et al 2020). If handling is not performed adequately in domestic animals, it will generate pain that, when not regulated, can set off severe stress that has physical, mental and behavioral effects (Flecknell et al 2011; McLennan et al 2019). These changes and possibly, the facial expressions associated with them are closely related to the pain and stress that hogs suffer during pre-slaughter processes. According to earlier research, these phenomena may also be linked to meat quality, since the pork obtained from pigs stressed by the slaughtering procedure may be pale, soft and exudative (PSE), or dark, firm and dry (DFD) (Van de Perre et al 2010).

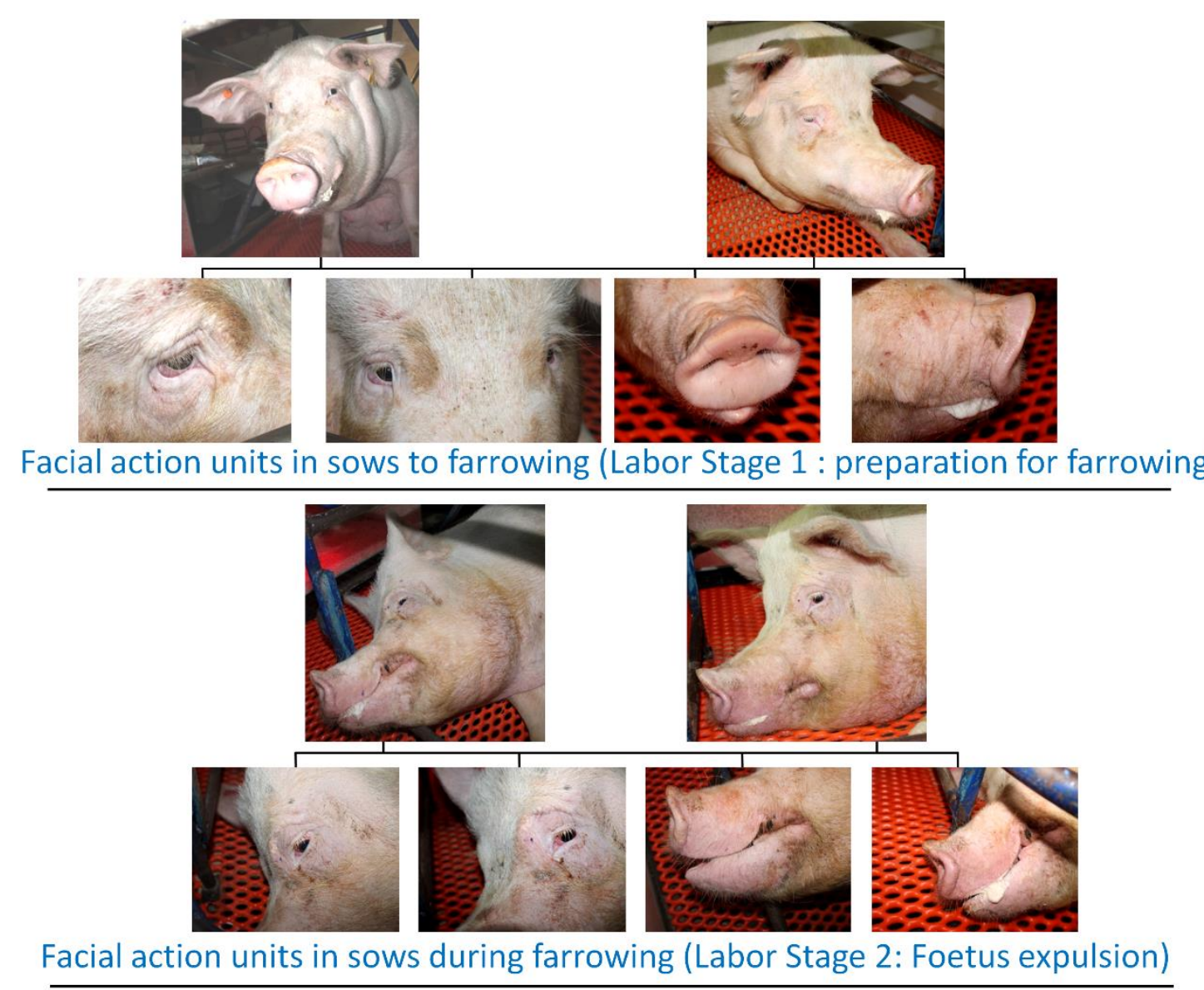

Figure 3 Example of facial action units in farrowing sows. It is important to define differences among these facial expressions more precisely. Before birthing, the eyes reflect a certain tension, and the snout is wrinkled, tense, and bulged, with a fold in the flatter area. During farrowing, the eyelids droop with eyes half-closed. The snout appears to be generally stretched and swollen. Analyses of farrowing require close-up photos of the eyes and snout to identify small differences in those two areas.

It is important to point out that pigs experience a whole series of events that can affect their emotional state and that of groups during transport. According to Vermeulen et al (2015), low-density population situations may result in more lesions due to falls, while high densities lead to more fighting. Observations in a study by Brown et al (2005) showed that during unloading, pigs manifest resistance and reluctance to leave the vehicle and take the first steps down the ramp, but these settings are characterized by a broad range of circumstances that can produce pain and fear that, on some occasions, may be manifested in aggressive behaviors. Therefore, experiences of negative emotions, stress, and pain are closely related to certain facial expressions.

In accord to Di Giminiani et al (2016), facial expression -or grimace- scales are precise and reliable tools for measuring pain during procedures or potentially-painful handling situations since aversive events can trigger emotions like fear (Rolls 2000; Reimert et al 2013). Speaking specifically of the causes of fear, it is clear that these will depend on the general characteristics of the event (novelty, 
physical particularities of the context, movement, intensity, duration, brusqueness, and proximity, among others (Gray 1991; Forkman et al 2007). Fear can be observed in animals during the pre-slaughter process if adequate indications for their welfare are not followed. In this respect, the prototype facial expression scale developed by Di Giminiani et al (2016) using piglets subjected to castration and tail-cropping can serve as the base for future evaluations of pain, emotions, and welfare using FAU during distinct handling processes throughout the life-cycle of swine, but primarily in the preslaughter period.
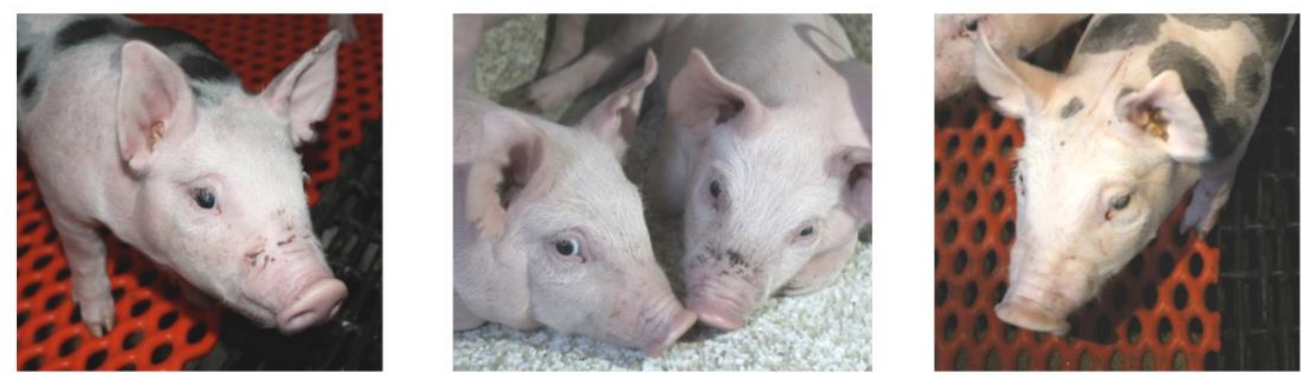

Piglets prior to weaning
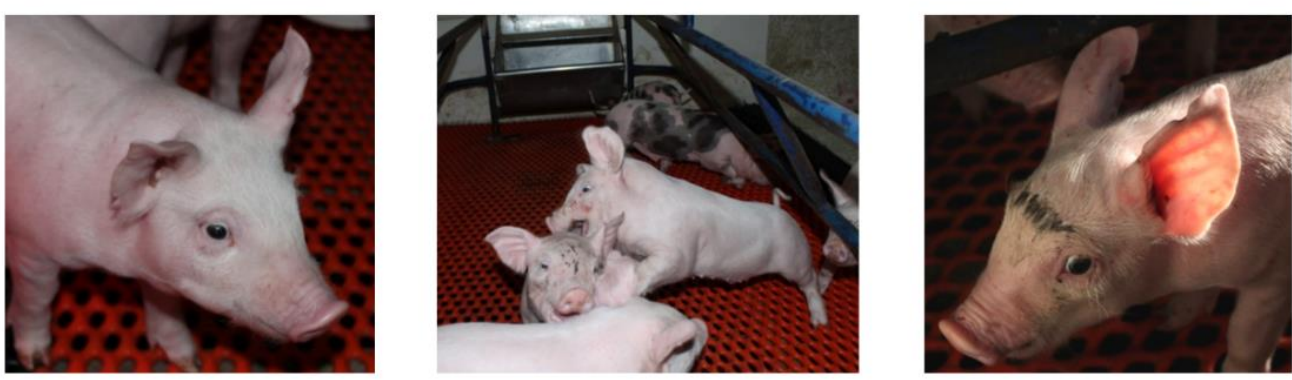

Piglets after separation from their mothers
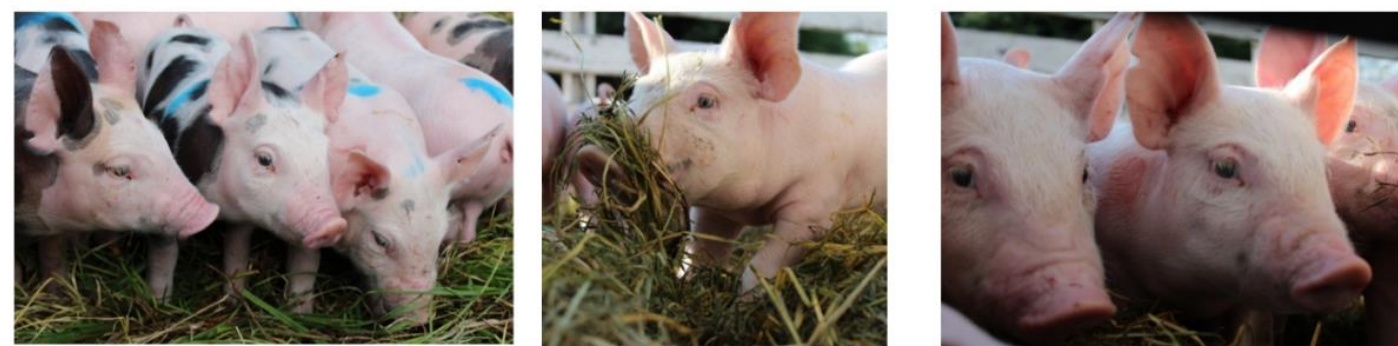

Piglets during transport with straw bedding
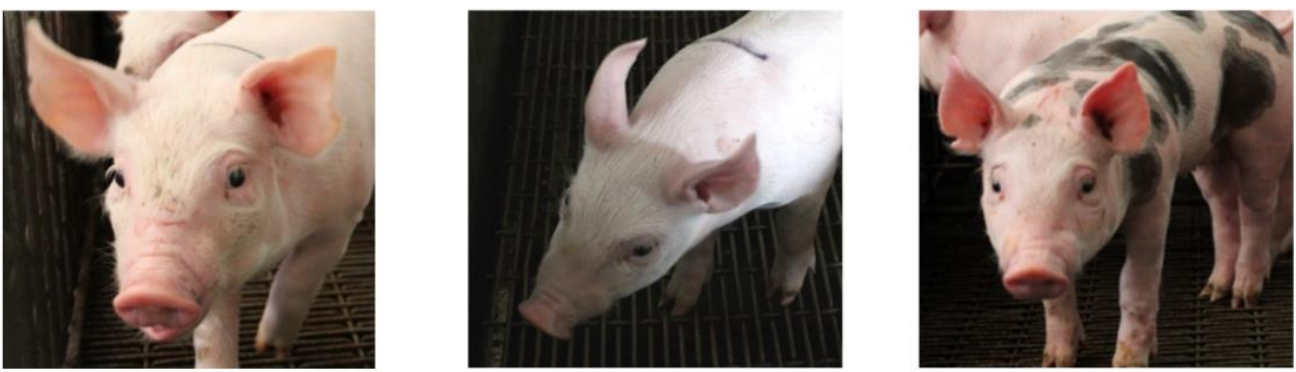

Pigs in the weaning area

Figure 4 Facial action units in weaned piglets. Attention should focus on the transition involved in the weaning process because piglets present a series of FAU that run from slight tension and an alert state before weaning, to agitation, orbital tension, and even fighting upon separation from their dams. An apparent state of relaxation and distraction emerges in the transport vehicle if it is enriched with a distractor. Finally, the return of ocular tension and retraction of the ears towards the caudal zone are evident. 
Before slaughter, the handling of hogs is usually performed in groups, a situation in which animals may experience anxiety upon perceiving signals from nearby conspecifics that are frightened or experience pain during transport or slaughter; that is, the condition of 'emotional contagion' mentioned earlier (Edgar et al 2011). This can modify facial expressions that are observable in pigs because they are a social species in which fear can be induced by such stimuli (Forkman et al 2007). Finally, Di Giminiani et al (2016) warn that the changes observed in grimaces influenced by fear, anxiety, stress, and pain can be interrelated with more than just one emotional state or form of excitation.

\section{Final Considerations}

Interpreting facial expressions constitutes an important strategy for evaluating the welfare of pigs. It serves as an indicator of emotions (positive and negative) throughout the animals' lives, but it may also be significant concerning communication and interaction in large groups of animals like pigs, which form a social species. Researchers must keep in mind that all emotional experiences are processed by the limbic system and, therefore, entail both physical and mental responses. To date, the only proposed facial expression scale we have is based on painful events in piglets (piglet grimace scale), but it can serve as the basis for future research in distinct contexts by providing information on the FAU characteristic of pigs according to their facial musculature. Today, we can only relate these FAU to painful events that cause stress and negative emotions reflected in those expressions, especially during handling before slaughter, though during that process, it is difficult to take photographs because of the speed with which it is performed and the size of the groups involved. In conclusion, developing a facial expression scale based on this event would provide a new model for evaluating animal welfare and assessing a particularly important factor that affects meat quality.

\section{Conflict of Interest}

The authors declare that they have no conflict of interest.

\section{References}

Becerril-Herrera M, Alonso-Spilsbury M, Lemus-Flores C, GuerreroLegarreta I, Olmos-Hernández A, Ramírez-Necoechea R, MotaRojas D (2009) CO2 stunning may compromise pigs welfare compared with electrical stunning. Meat Science 81:233-237.

Bennett V, Gourkow N, Mills DS (2017) Facial correlates of emotional behaviour in the domestic cat (Felis catus). Behavioural Processes 141:342-350.

Boissy A, Manteuffel G, Jensen M, Oppermann R, Spruijt B, Keeling L, Aubert A (2007) Assessment of positive emotions in animals to improve their welfare. Physiology and Behavior 92:375-397.
Boumans I, Bokkers E, Hofstede G, \& De Boer I. (2015) Understanding feeding patterns in growing pigs by modelling growth and motivation. Applied Animal Behaviour Science 171:69-80.

Boumans I, De Boer I, Hofstede G, \& Bokkers E (2018) How social factors and behavioural strategies affect feeding and social interaction patterns in pigs. Physiology and Behavior 194:23-40.

Brown S, Knowles T, Wilkins L, Chadd S, Warriss P (2005) The response of pigs to being loaded or unloaded onto commercial animal transporters using three systems. The Veterinary Journal 170:91-100.

Brown S, Klaffenbock M, Macleod I, Burnett A (2015) Evidence for litter differences in play behaviour in pre-weaned pigs. Applied Animal Behaviour Science 172: 17-25.

Bruce LL, Neary T J (1995) The limbic system of tetrapodes: a comparative analysis of cortical and amygdala populations. Brain, Behavior and Evolution 46:224-34.

Brudzynski SM (2010) Communication of Emotions in Animals. Encyclopedia of Behavioral 1:302-307.

Caeiro CC, Burrows AM, Waller BM (2017) Development and application of CatFACS: are human cat adopters influenced by cat facial expressions?. Applied Animal Behaviour Science 189:66-78.

Camerlink I, Coulange E, Farish M, Baxter EM, Turner SP (2018) Facial expression as a potential measure of both intent and emotion. Scientific Reports 8:1-9.

Carcò G, Dalla M, Carraro L, Latorre M, Fondevila M, Gallo L, Schiavon S (2018) Influence of mild feed restriction and mild reduction in dietary amino acid content on feeding behaviour of group-housed growing pigs. Applied Animal Behaviour Science 198: 27-35.

Dalla-Costa E, Minero M, Lebelt D, Stucke D, Canali E, Leach MC (2014) Development of the horse grimace scale (HGS) as a pain assessment tool in horses undergoing routine castration. PLOS ONE 9:e92281.

Darwin C (1872) The expression of the emotions in man and animals (1st ed). London, John Murray, Albemarle street 1872.

Descovich K, Wathan J, Leach M, Buchanan-Smith H, Flecknell P, Farningham D, Vick, SJ (2017) Facial expression: An under-utilized tool for the assessment of welfare in mammals. ALTEX 34:409-29.

Di Giminiani P, Brierley VL, Scollo A, Gottardo F, Malcolm EM, Edwards SA, Leach MC (2016) The Assessment of facial expressions in piglets undergoing tail docking and castration: toward the development of the piglet grimace scale Frontiers in Veterinary Science 3:100.

Dyce KM, Sack WO, Wensing CJG (2010) Anatomia Veterinaria. México, McGraw-Hill.

Edgar J, Lowe J, Paul E, Nicol C, (2011) Respuesta materna aviar a la angustia de los pollitos. Proceedings of the Royal Society B. Biological Science 278:3129-3134.

Farb CR, LeDoux JE (1998) NMDA and AMPA receptors in the lateral nucleus of the amygdala are postsynaptic to auditory thalamic afferents. Synapse 27:106-21.

Ekman P, Friesen W (1978) Facial Action Coding System: a Technique for the Measurement of Facial Movement. CA: Consulting Psychologists Press, Palo Alto.

Figueroa J, Solá-Oriol D, Manteca X, Pérez J, Dwyer D (2015) Anhedonia in pigs? Effects of social stress and restraint stress on sucrose preference. Physiology and Behavior 151:509-515.

Finka LR, Luna SP, Brondani JT, Tzimiropoulos Y, McDonagh J, Farnworth MJ, Mills DS (2019) Geometric morphometrics for the 
study of facial expressions in non-human animals, using the domestic cat as an exemplar. Scientific Reports 9:9883.

Flecknell P, Leach M, Bateson M (2011) Affective state and quality of life in mice. Pain 152:963-964.

Flores-Peinado S, Mota-Rojas D, Guerrero-Legarreta I, MoraMedina P, Cruz-Monterrosa R, Gómez J, Hernández MA, CruzPlayas J, Martínez-Burnes J (2020) Pre-slaughter stress in pigs, infrared thermography assessment and meat quality. International Journal of Animal Science and Medicine 8:(Accepted).

Forkman B, Boissy A, Meunier-Salaün M, Canali E, Jones R (2007) A critical review of fear tests used on cattle, pigs, sheep, poultry and horses. Physiology and Behavior 92:340-374.

Frías D 2015 Evaluación de métodos utilizados para medir la palatabilidad en cerdos de recría. MV Thesis, Universidad de Chile, Chile.

Fridlund AJ (1994) Human facial expression: An evolutionary view. USA, Academic Press.

Friel M, Kunc, HP, Griffin K, Asher L, Collins LM (2019) Positive and negative contexts predict duration of pig vocalisations. Scientific Reports 9:2062.

Gleerup KB, Forkman B, Lindegaard C, Andersen PH (2015) An equine pain face. Veterinary Anaesthesia and Analgesia 42:103-114.

González-Lozano M, Mota-Rojas D, Orihuela A, Martínez-Burnes J, Di Francia, Braghieri A, Berdugo GJ, Mora MP, Ramírez NR, Napolitano F (2020) Behavioral, physiological and reproductive performance in buffaloes during eutocic and dystocic parturitions. Applied Animal Science 36:407-422.

Gray JA (1991) The Neuropsychology of Temperament. In Strelau, J., \& Angleitner, A., (Eds.). Explorations in Temperament. Perspectives on Individual Differences (pp. 105-128). Boston: Springer.

Häger C, Biernot S, Buettner M, Glage S, Keubler LM, Held N, Bleich EM, Otto K, Müller CW, Decker S, Talbot SR, Bleich A (2017) The Sheep Grimace Scale as an indicator of post-operative distress and pain in laboratory sheep. Plos One

Herskin MS, Di Giminiani P (2018) Pain in pigs: characterisation, mechanisms and indicators. Advances in Pig Welfare 325-355.

Holden E, Calvo G, Collins M, Bell A, Reid J, Scott EM, Nolan AM (2014) Evaluation of facial expression in acute pain in cats. Journal of Small Animal Practice 55:615-21.

Hernández-Avalos I, Mota-Rojas D, Mora-Medina P, MartínezBurnes J, Casas-Alvarado A, Verduzco-Mendoza A, Lezama-García K, Olmos-Hernández A (2019) Review of different methods used for clinical recognition and assessment of pain in dogs and cats. International Journal of Veterinary Science and Medicine 7:43-54.

Horstmann G (2003) What do facial expressions convey: Feeling states, behavioral intentions, or actions requests? Emotion 3:150-166.

Iglesias S, Del Castillo A, Muñoz J (2016) Reconocimiento facial de expresión emocional: diferencias por licenciaturas. Acta de Investigación Psicológica 6:2494-2499.

Julle-Danière É, Micheletta J, Whitehouse J, Joly M, Gass C, Burrows AM, Waller BM (2015) MaqFACS (Macaque Facial Action Coding System) can be used to document facial movements in Barbary macaques (Macaca sylvanus). PeerJ 3:e1248.

Keating SCJ, Thomas AA, Flecknell PA, Leach MC (2012) Evaluation of EMLA Cream for Preventing Pain during Tattooing of Rabbits: Changes in Physiological, Behavioural and Facial Expression Responses. PLOS ONE 7:e44437.
Krugmann K, Warken F, Krieter J, Cyzcholl I (2019) Are behavioral test capable of measuring positive affective states in growing pigs? Animals 9:274.

Lane S. M, Briffa, M (2017) The price of attack: rethinking damage costs in animal contests. Animal Behaviour 126:23-29.

Langford DJ, Bailey AL, Chanda ML, Clarke SE, Drummond TE, Echols S, Glick S, Ingrao J, Klassen-Ross T, LaCroix-Fralish ML, Matsumiya L, Sorge RE, Sotocinal SG, Tabaka JM, Wong DM, van den Maagdenberg AMJ, Ferrari MD, Craig KD, Mogil JS (2010) Coding of facial expressions of pain in the laboratory mouse. Nature Methods 7:447-449.

Leliveld L, Pupjan S, Tuchdcherer A, Puppe B (2016) Behaviural and physiological measures indicate subtle variations in the emotional valence of young pigs. Physiology andBehavior 157:116-124. htt

Lezama-García K, Orihuela A, Olmos-Hernández A, Reyes-Long S, Mota-Rojas D (2019a) Invited review: Facial expressions and emotions in domestic animals. CAB Reviews 14:1-12.

Lezama-García K, Maiti Ch, Mota-Rojas D, Martínez-Burnes J., Barrios-García H, Gazzano A (2019b) Maternal behaviour in domestic dogs. International Journal of Veterinary Science and Medicine 7:20-30.

Manteca X, Temple D, Mainau E, Llonch P (2017) Assessment of pain in sheep. The Farm Animal Welfare Fact Sheet. FAWEC-Farm Animal Welfare Education Centre. 17.

Marcet-Rius M, Pageat P, Bienboire-Frosini C, Teruel E, Monneret P, Leclercq J, Lafont-Lecuelle C, Cozzi A (2018) Tail and ear movements as possible indicators of emotions in pigs. Applied Animal Behaviour Science 205:14-18.

Marcet-Rius M, Fábrega E, Cozzi A, Bienboire-Frosini C, Descout E, Velarde A, Pageat P (2019a) Are tail and ear movements indicators of emotions in tail-docked pigs in response to environment enrichment? Animals 9:449.

Marcet-Rius M, Kalonji G, Cozzi A, Bienboire-Frosini C, Monneret P, Kowalczyk I, Teruel E, Codecasa E. Pageat P (2019b) Effects of straw provision, as environment enrichment, on behavioural indicators of welfare and emotions in pig reared in an experimental system. Livestock Science 21:89-94.

Maselyne J, Saeys W, Van Nuffel A (2015) Review: Quantifying animal feeding behaviour with a focus on pigs. Physiology and Behavior 138:37-51.

McLennan K (2018) Why pain is still a welfare issue for farm animals, and how facial expression could be the answer. Agriculture $8: 127$.

McLennan KM, Miller AL, Dalla Costa E, Stucke D, Corke MJ, Broom DM, Leach MC (2019) Conceptual and methodological issues relating to pain assessment in mammals: The development and utilisation of pain facial expression scales. Applied Animal Behaviour Science 217:1-15.

Merskey H, Bogduk N (1994) Classification of chronic pain: descriptions of chronic pain syndromes and definitions of pain terms (2nd ed.). Seattle, IASP Press.

Mellor DJ (2012) Animal emotions, behaviour and the promotion of positive welfare states. New Zealand and Veterinary Journal 60:1-8.

Mellor D, Beausoleil N (2015) Extending the 'Five Domains' model for animal welfare assessment to incorporate positive welfare states. Animal Welfare 24:241-53.

Molero A, 2007 Aprendizaje aversivo gustativo: Características, paradigma y mecanismos cerebrales. Anales de Psicología-Spain 23:57-64. 
Mota-Rojas D, Becerril M, Lemus C, Sanchez P, Gonzalez M, Olmos SA, Ramirez R, Alonso-Spilsbury M (2006) Effects of mid-summer transport duration on pre- and post-slaughter performance and pork quality in Mexico. Meat Science 73:404-412.

Mota-Rojas D, Becerril-Herrera M, Alonso-Spilsbury M, FloresPeinado S, Ramírez-Necoechea R, Ramírez JA, Mora-Medina, Soní E, Trujillo-Ortega ME (2012) Effects of long distance transport and CO2 stunning on critical blood values in pigs. Meat Science 90:893898 .

Mota-Rojas D, Velarde A, Maris-Huertas S, Cajiao PMN (2016). Editors. In: Animal welfare, a global vision in Ibero-America. [Bienestar Animal una visión global en Iberoamérica]. 3rd ed. Barcelona, Spain. Elsevier; p. 516.

Mota-Rojas D, López A, Martínez-Burnes J, Muns R, VillanuevaGarcía D, Mora-Medina P, Gonzalez-Lozano M, Olmos HA, and Ramírez NR (2018a). Invited review: Is vitality assessment important in neonatal animals? CAB Reviews 13(036):1-13.

Mota-Rojas D, Orihuela A, Strappini-Asteggiano A, Cajiao PMN, Aguera-Buendia E, Ghezzi M, Alonso, SML (2018b) Teaching animal welfare in veterinary schools in Latin America. International Journal of Animal Science and Medicine 6:131-40.

Mota-Rojas D, Lezama GK, Alavez VB, Flores PK, González LC, Morales FL, Nava AJ, Mora-Medina P (2018c). The language of animals: importance of the tail and ears. Agro Meat, Buenos Aires, Argentina. Dic, 2018. p.1-10.

Mota-Rojas D, Martínez-Burnes J, Napolitano F, Domínguez MM, Guerrero LI, Mora-Medina P, Ramírez NR, Lezama GK, GonzálezLozano M (2020a) Invited review: Dystocia: Factors affecting parturition in domestic animals. CAB Rev. 15:1-14.

Mota-Rojas D, Broom DM, Orihuela A, Velarde A, Napolitano F, Alonso-Spilsbury M (2020b) Effects of human-animal relationship on animal productivity and welfare. Journal of Animal Behaviour and Biometeorology 8:196-205.

Müller BR, Souza SV, Biscarra-Bellio JC, Maiolino-Molento CF (2019) Facial expression of pain in Nellore and Crossbred beef cattle. Journal of Veterinary Behavior 34:60-65.

Murphy E, Nordquist R, Van der Staay F (2014) A review of behavioural methods to study emotion and mood in pigs, Sus scrofa. Applied Animal Behaviour Science 159:9-28.

Nalon E, Maes D, Piepers S, Taylor P, Van Riet MMJ, Janssens GPJ, Tuyttens FAM (2015) Factors affecting mechanical nociceptive thresholds in healthy sows. Veterinary Anaesthesia and Analgesia

Núñez V 2015 Estudio de palatabilidad en cerdos de recría en base a soluciones de glutamato monosódico. MV Thesis, Universidad de Chile, Chile.

Orihuela A, Mota-Rojas D, Velarde A, Strappini-Asteggiano A, Thielo de la Vega L, Borderas-Tordesillas F, Alonso-Spilsbury M (2018) Invited review: environmental enrichment to improve behaviour in farm animals. CAB Reviews 13:1-25.

Parr L, Waller B, Burrows A, Gothard K, Vick S (2010) MaqFACS: a muscle-based facial movement coding system for the Rhesus macaque. American Journal of Physical Anthropology 143:625-630.

Parr LA, Waller BM, Vick SJ, Bard KA (2007) Classifying chimpanzee facial expressions using muscle action. Emotion 7:172.

Paul E, Harding E, Mendl M (2005) Measuring emotional processes in animals: the utility of a cognitive approach. Neuroscience Biobehavioral Reviews 29:469-491.
Paul E, Mendl M (2018) Animal emotion: Descriptive and prescriptive definitions and their implications for a comparative perspective. Applied Animal Behaviour Science 205:202-209.

Reimert I, Bolhuis E, Rodenburg B (2013) Indicators of positive and negative emotions and emotional contagion in pigs. Physiology Behaviour 109:42-50.

Rolls T (2000) The Brain Emotion. Trends in Cognitive Sciences, Cambridge University Press, 3:281- 282.

Rutherford KMD (2002) Assessing pain in animals. Animal Welfare 11:31-53.

Sneddon LU, Elwood RW, Adamo SA, Leach MC (2014) Defining and assessing animal pain. Animal Behaviour 97:201-212.

Sotocinal SG, Sorge RE, Zaloum A, Tuttle AH, Martin LJ, Wieskopf JS, Mapplebeck JCS, Wei P, Zhan S, Zhang S, McDougall JJ, King OD, Mogil JS (2011) The Rat Grimace Scale: A Partially Automated Method for Quantifying Pain in the Laboratory Rat via Facial Expressions. Molecular Pain 7:55.

Rutherford KMD, Donald RD, Lawrence AB, Wemelsfelder F (2012) Qualitative Behavioural Assessment of emotionality in pigs. Applied Animal Behaviour Science 139:218-224.

Temple D, Manteca X, Velarde A, Dalmau A (2011) Assessment of animal welfare through behavioural parameters in Iberian pigs in intensive and extensive conditions. Applied Animal Behaviour Science 131:29-39.

Tuttle AH, Molinaro MJ, Jethwa JF, Sotocinal SG, Prieto JC, Styner MA, Mogil JS, Zylka MJ (2018) A deep neural network to assess spontaneous pain from mouse facial expressions. Molecular Pain 14:1-19.

Van de Perre V, Permentier L, De Bie S, Verbeke G, Geers G (2010) Effect of unloading, lairage, pig handling, stunning and season on $\mathrm{pH}$ of pork. Meat Science 86:931-937.

Vermeulen L, Van de Perre V, Permentier L, De Bie S, Verbeke G, Geers R (2015) Pre-slaughter handling and pork quality. Meat Science 100:118-123.

Viscardi AV, Hunniford M, Lawlis P, Leach M, Turner PV (2017) Development of a piglet grimace scale to evaluate piglet pain using facial expressions following castration and tail docking: a pilot study. Frontiers in Veterinary Science 4:51.

Viscardi AV, Turner PV (2018) Efficacy of buprenorphine for management of surgical castration pain in piglets. BMC Veterinary Research 14:318.

Waller BM, Whitehouse J, Micheletta J (2017) Rethinking primate facial expression: A predictive framework. Neuroscience Biobehavioral Reviews 82:13-21.

Waller BM, Julle-Daniere E, Micheletta J (2020) Measuring the evolution of facial 'expression' using multi-species FACS. Neuroscience Biobehavioral Reviews 113:1-11.

Wathan J, Burrows AM, Waller BM, McComb K (2015) EquiFACS: the equine facial action coding system. Plos One 10:e0137818.

Whittaker AL, Howarth GS (2014) Use of spontaneous behaviour measures to assess pain in laboratory rats and mice: How are we progressing? Applied Animal Behaviour Science 151:1-12.

Whittaker AL, Marsh LE (2019) The role of behavioural assessment in determining 'positive' affective states in animals. CAB Reviews 14:1-13. 